\title{
Entscheidungen in Kirchensachen
}

\section{seit 1946}

Begründet von

Prof. Dr. Dr. Carl Joseph Hering $† \quad$ Dr. Hubert Lentz

Herausgegeben von

Prof. Dr. Manfred Baldus

Vorsitzender Richter

am Landgericht Köln a. D.
Prof. Dr. Stefan Muckel

Universitätsprofessor an der Universität zu Köln

\author{
in Verbindung mit dem \\ Institut für Kirchenrecht \\ und rheinische Kirchenrechtsgeschichte \\ der Universität zu Köln
}





\section{Entscheidungen in Kirchensachen}

seit 1946

55. Band

1. 1.-30. 6. 2010

De Gruyter 
ISBN 978-3-11-030905-8

Bibliografische Information der Deutschen Nationalbibliothek

Die Deutsche Nationalbibliothek verzeichnet diese Publikation in der Deutschen Nationalbibliografie; detaillierte bibliografische Daten sind im Internet über http://dnb.dnb.de abrufbar.

(C) 2014 Walter de Gruyter GmbH, Berlin/Boston

Druck: Hubert \& Co. GmbH \& Co. KG, Göttingen

(@) Gedruckt auf säurefreiem Papier

Printed in Germany

www.degruyter.com 